\title{
CONNECTING GRADUATE STUDENTS TO VIRTUAL GUESTS THROUGH ASYNCHRONOUS DISCUSSIONS - ANALYSIS OF AN EXPERIENCE
}

\author{
D. Siva Kumari, Ed. D.
}

Assistant Dean and Director of Programs

School of Continuing Studies, MS 550

Rice University

Houston, Texas 77251-1892

Phone: 713-348-4803; Fax: 713-348-5213

siva@,rice.edu

http://www.rice.edu/ skumari

\begin{abstract}
Information technologies provide unique opportunities for higher education faculty to rethink the resources that are available to re-envision their pedagogical techniques. One such promise is the ability of the faculty member to invite virtual guest speakers or experts into the graduate course through web-based conferencing. The virtual guest can host asynchronous interactive discussions with students in the course for a specified period of time. These technologies provide students with the ability to interact with guests in new ways by expressing individual concerns and discussing them without time and place constraints. This paper describes in quantitative and qualitative terms one such experience in a graduate course where three virtual guests were invited to interact with the students over the eleven-week course.
\end{abstract}

\section{KEY WORDS}

Online learning, web-based learning, pedagogy, web-based conferencing, higher education

\section{INTRODUCTION}

Information technologies continue to receive rave reviews as technologies that can change and revitalize existing pedagogies and enabling entirely new conceptualizations in higher education teaching and learning settings. These technologies provide promise for rethinking resources available to faculty and students in a traditional campus-based or online course. One such promise and affordance is the ability of the instructor to invite virtual guest speakers or experts into the graduate course through web-based conferencing. The virtual guest can host asynchronous interactive discussions with students in the course for a specified period of time. Akin to the traditional guest speaker, the virtual guest host can be invited by the instructor to fill an instructional need. However, markedly different from interactions with guest speakers in a traditional classroom the dialogue, between guests and students, is not limited in terms of either time or to a few voluble students. Web-based conferencing allows each student to have an equal opportunity for interaction with the guest. Additionally, these technologies provide students with the ability to interact with guests in new ways by expressing individual concerns and discussing them without 
time and place constraints. Such communications are a much-heralded advantage of Asynchronous Learning Networks (ALNs) [1].

This paper provides an analysis of student interactions with three virtual guests who hosted asynchronous conversations in a graduate course. The students were mostly K-12 teachers who were enrolled in a course, Integrating Technology into the Curriculum. The course was taught at a large urban public university in a southern state in the United States. The virtual guests were teachers themselves from the local community who had gained expertise in integrating technology into the curriculum and demonstrated leadership in the arena. This paper will present the analysis of discussions that students had with the three guest hosts during the summer semester. Informal feedback from graduate students indicated that this aspect of the course excited them. Based upon their recommendations, this format was continued in an online version of this course that was offered the following semester. The formal analysis, presented here, will provide quantitative evidence of the interactions between the students and the virtual guest hosts. Additionally, it will include a brief discussion about the qualitative nature of interactions and present evidence to support the analysis.

\section{BACKGROUND}

\section{A. Creating Conversational Spaces in Learning Environments}

When rethinking teaching and using technology as a tool to enhance learning, the course environment can be re-conceptualized to extend beyond the normal processes that occur in a traditional classroom. Webbased conferencing allows us to think anew about the role of guest speakers/hosts in a course. As Couples [2] indicates, we can "fabricate sites/places/zones/spaces" in the virtual environment to accomplish different functions. This paper argues that faculty as virtual architects of the course can construct digital spaces for guests where they can communicate with students by introducing new topics, discussing practical aspects of the content or by providing renewed dialogue about subjects previously visited in the course.

As Owston [3] argues, "the key to improved learning with the web appears to lie within how effectively the medium is exploited in the teaching-learning situation" (p. 4). He continues that the "result (of webbased conferencing) is richer, more thoughtful discussions, not because of the medium but because of the way the instructor stimulated and orchestrated the environment made possible by the medium." This paper argues that the instructor can employ this medium to accomplish stimulated discussions by introducing guests that will supplement the role of the instructor in substantial ways by accomplishing some of the instructional goals of the course.

Trentin [4] suggests that these notions are an innovative approach to consider particularly in the context of teacher professional development where cooperative learning occurs as a result of intensive use of interpersonal communication among experts, tutors and students. Others discuss connection to experts in the form of structured interviews [5]. Learners who participate in inquiries with mature communities of practitioners are engaged in a transformative form of conversational learning. Pea describes this foregrounding of the conversation as 'transformative' - one in which both parties participating in the dialogue are transformed, in a two-way dynamic system [6]. The experience in this course has been that both students and guests found themselves to be engaged in dynamic and equal conversations that had a stream of interactive content. The conversations adhered more to the transformative model rather than the transmission model of discourse - that is to say that the conversational flow and exchange of ideas was bidirectional between students and guests. 


\section{B. The Value of Interactions in Online Environments}

A wealth of literature exists about the value of online asynchronous teacher-to-student and student-tostudent discussions in graduate courses. High levels of communication among students and active learning processes correlate positively with the way students judge the outcome of the course [7]. The need for high-level faculty-student interaction is discussed by many authors as an important aspect of virtual learning environments [8], [9], [10], [11], [12], [13], [14], [15], [16], [17]. However, relatively little research exists about the use of virtual guest hosts in asynchronous discussions in graduate courses. In online professional communities through web-based conferencing and listservs, we regularly connect with other colleagues and experts to discuss pertinent issues. Extending these notions to a graduate course and modifying the structure of the online community to suit the needs of the course environment, seems a natural extension.

Green and Gilbert [18] discuss access to resources as an important advantage provided by information technology to improve pedagogy and the curriculum. This access is described in terms of image databases, statistical databases and remote libraries. While these are undoubtedly exciting resources for an instructor and students, the potential to connect students to experts, who can enhance learning in a graduate course, can be also be conceived as a dynamic and interactive pedagogical strategy. Boettcher and Cartwright [19] discuss three dimensions of interactions that are possible in a web-based course: student-to-student, teacher-to-student and student-to-resource. In this last domain student-to-resource, they discuss interaction with resources, content resources, similar in nature to those discussed by Green and Gilbert above. Experts, however, can serve as a viable and valid form of dynamic and real-world knowledge resources. Noam [20] proposes video servers stored with lectures by outstanding scholars. This form of media resource is exciting and may soon a practical possibility when bandwidth issues are eliminated. In the interim, a viable low-bandwidth and highly interactive alternative is to introduce guests who are willing to interact with students in a course through web-based asynchronous communication. This pedagogical strategy can be implemented to achieve high-end learning outcomes in a cost-effective manner. It is also an implementation of computer conferencing one of the major paradigms currently in use in ALNs [21].

Dede [22] uses the term 'knowledge webs' to indicate distributed access to experts and other resources. Rowntree [23] extends effective online communication to include discussions of shared life experience or work-based activities. The guest hosts in this experiment served to bring in their experiences into the classroom and thus extend the 'resources' available to the students. Simonson [24] argues that those who implement online learning environments should strive to make the experience at least equal to that of a traditional classroom. This paper contends that the implementation of guest hosts in a virtual environment can be better than the version possible in a traditional class. In a face-to-face course, the guest speaker is limited to 1-2 hours of lecture followed by an interactive experience with one or two voluble members of the class. From this experiment with online guest hosts, interactive contact with the expert is available to more than a few voluble students and brings into play the many-many communications that are typical of online dialogues.

Much has been written about the role of the instructor in moderating online courses [25], [26], [27] but there is very little information about how guest hosts need to be prepared to interact in these environments. This paper will also discuss practical suggestions for faculty interested in preparing the online environment for student-guest interactions. 


\section{THE EXPERIENCE OF USING VIRTUAL GUEST HOSTS}

\section{A. The Context for the Implementation of Guest Hosts}

The graduate course into which the guest hosts were invited is entitled 'Integrating Technology into the Curriculum.' It is open to Masters and Doctoral level students in the College of Education. It is thus also open to K-12 teachers in the teacher education program within the college. The group of 15 students enrolled in the course consisted of twelve students who are teachers in local K-12 schools, two full-time graduate students, and one student who worked in higher education. The twelve K-12 teachers represented elementary and middle schools. There were ten females and five males in the course. Students entered the course with a diverse set of technological skills ranging from novice to sophisticated endusers. Their range of K-12 teaching experience was also varied and included first time teachers, those entering the teaching profession as a second career and experienced teachers. This semester long course consisted of eleven weekly four-hour face-to-face sessions. All of the course materials were available online since this course was being offered as an entirely online course the following semester.

\section{B. The Decision to Use Guests}

Students are generally overwhelmed when asked to think about integrating technology into the curriculum. This feeling is generally confounded when asked to think with newly introduced technology tools and to demonstrate evidence of this process at the application level by the end of the semester by producing technology integrated curricular products. Guest hosts were invited by the instructor to address a variety of educational needs in such a learning context. The primary goal was to connect students to other teachers in the community who have successfully integrated technology into their classroom and could provide real-life examples to students. By enabling students to view models of integration, presented by the guests, and asking them to conduct an inquiry of the successful process of integration, students were able to articulate their concerns about integrating technology into the classroom. Additionally, the instructor also wanted to introduce into the course topics such as gender equity, staff development, the role of the administration and other topics in which the guests had demonstrated particular expertise.

\section{The Technology}

HyperGroups, the asynchronous web-based conferencing system used works similarly to many other such systems [27]. Users post messages using web-based forms, in which they enter their names, email addresses and the text or body of the message. If the message is about a new topic, the software starts a new thread and user responses to this thread are indented. Thus the threading provides visual cues regarding the number of threads and the number of responses per thread. The software enables users to post original messages, reply to posts, attach files and view the messages by date, thread, and author.

Students in this course were required to use HyperGroups for other aspects of this course. For instance, each team had their own HyperGroup in which to conduct discussions about their particular project. Additionally, all students were expected to participate in a central HyperGroup where there were discussions initiated by the instructor or the students. The interface (Figure 1) to all these discussion groups was presented on a single webpage available in the online course materials. The use of different HyperGroups provides students with a sense of entering different discussion spaces for different purposes. 


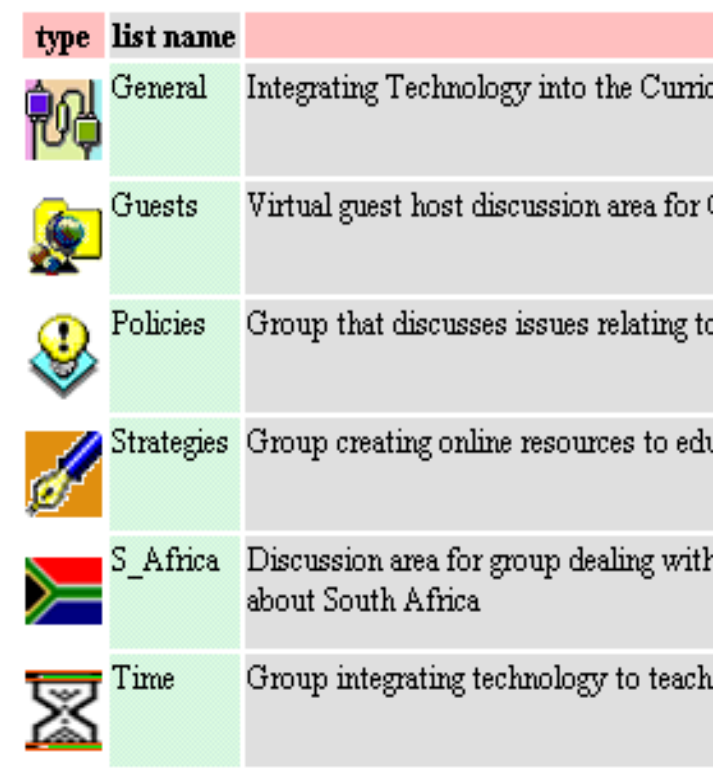

Figure 1: A partial image of the screen that provided access to the HyperGroups in the course

\section{Quantitative Analysis of the Summer Experience}

As indicated earlier three guest hosts ( 2 female, 1 male) were invited to host the discussion space for a week. A few additional qualifiers will indicate the nature of their expertise and experience. The first guest host is a former high school mathematics teacher and is now a university-based administrator of professional development programs for K-12 teachers. The second is a former middle school science teacher who integrated technology into his teaching. He is currently an assistant principal in an elementary school. The third is a high school computer science teacher. The instructor is familiar with each of these guests and is aware that all three are facile in using information technologies, particularly communication technologies. The guests were introduced in week 3, 5 and 7 of an eleven-week summer course and were asked to host for seven days from Thursday to the following Wednesday. The preparation of these hosts for participation in these spaces will be discussed in this paper, in a later section. A total of 199 messages were exchanged over the course of the three weeks among the group. Students were encouraged to participate in these discussions but this was a non-graded activity.

\section{The Quantity of Posts Among the Participants}

From the quantitative analysis provided it is evident that the guests were very responsive to the students. The guests made an average of $41.4 \%$ of the total postings for their session to the list compared to $54.1 \%$ posts of the students. The volume of student posts was consistent for all three guests who participated in separate weeks $(3,5$, and 7$)$ of this eleven-week course. 
Table 1: Quantity of posts per student and per guest (GH) per session.

\begin{tabular}{|c|c|c|c|c|c|c|c|}
\hline & \multirow{2}{*}{$\begin{array}{l}\text { Total number of } \\
\text { messages posted }\end{array}$} & \multicolumn{2}{|c|}{ Posts by Guests } & \multicolumn{2}{c|}{ Posts by Students } & \multicolumn{2}{c|}{ Posts by Instructor } \\
\cline { 3 - 8 } & & Number & $\begin{array}{l}\text { Percent of } \\
\text { the session }\end{array}$ & Number & $\begin{array}{c}\text { Percent of } \\
\text { the session }\end{array}$ & Number & $\begin{array}{c}\text { Percent of } \\
\text { the session }\end{array}$ \\
\hline GH1 (F) & 62 & 26 & 41.9 & 33 & 53.2 & 3 & 4.8 \\
\hline GH2(M) & 53 & 19 & 35.8 & 32 & 60.4 & 2 & 3.8 \\
\hline GH3 (F) & 84 & 39 & 46.4 & 41 & 48.8 & 4 & 4.8 \\
\hline Totals & 199 & 84 & 42.2 & 106 & 53.3 & 9 & 4.5 \\
\hline Average & $\mathbf{6 6 . 3}$ & $\mathbf{2 8}$ & $\mathbf{4 1 . 4}$ & $\mathbf{3 5 . 3}$ & $\mathbf{5 4 . 1}$ & $\mathbf{3}$ & $\mathbf{4 . 5}$ \\
\hline
\end{tabular}

The instructor's postings (4.5\%) reflect the intentionally minimal role adopted in this setting. The instructor restricted her role to an initial post introducing each guest, making technical suggestions where necessary and making a final post thanking each guest at the end of their week of hosting. Her primary role was to select the guests, provide them with the scope of topics that would be appropriate for the course, and some useful background about the students. Additionally, once the sessions were in progress, the instructor exchanged a few personal emails with each guest to make clarifications, provide encouragement, guidance and to suggest additional topics for discussion where needed.

\section{Individual Student Participation}

As presented in Table 2, postings from the students were fairly well distributed and no one student dominated among all guests. Students who were more vocal with one guest did not maintain a similar pattern with the other guests. Students were able to post their specific questions to the guest and receive a response and in many cases continue a longer dialogue. Additionally non-participation was not consistent. Only one student chose not to participate in any guest discussions. Two others chose not to participate with two of the three guest hosts. While five students chose not to participate with at least one guest. One source of explanation is that some students were not available for the weeklong out-of-class non-graded discussions. Another explanation is that not all students were interested in all guests or all topics. Despite the small sample, these results are aligned with those of Selfe [28] who reported that women tend to interact more in CMC activities than men. As can be seen in Tables 1 and 2, this seems to hold true for both the host and student responses in the guest hosting sessions. There were 4 students (all female) who posted between 10 and 15 responses, 6 students ( 5 female, 1 male) who posted between 5 and 9 responses and 4 students who posted between 1 and 4 responses ( 2 female, 2 male).

Encouraging collaborative student interactions provides a means of developing reflective thinking among learners and broadens their experiences and perspectives [29]. It should be noted that since the hosting included the weekend (Thursday - Wednesday) it may have allowed more time for deliberated responses. Additionally, since this was a summer session, students had time away from their schools and full-time jobs to participate more fully. It will be interesting to study if the same volume and pattern continues in the Fall session with students with similar backgrounds. 
Table 2: Number of student postings by each student per guest host (GH) arranged in descending order.

\begin{tabular}{|l|c|c|c|c|c|}
\hline Student & Gender & GH1 & GH2 & GH3 & $\begin{array}{c}\text { Total number of } \\
\text { messages posted }\end{array}$ \\
\hline S13 & F & 3 & 6 & 6 & 15 \\
\hline S3 & F & 9 & 0 & 6 & 15 \\
\hline S2 & F & 5 & 2 & 6 & 13 \\
\hline S12 & F & 3 & 5 & 2 & 10 \\
\hline S15 & F & 4 & 5 & 0 & 9 \\
\hline S4 & F & 2 & 3 & 3 & 8 \\
\hline S6 & F & 3 & 3 & 1 & 7 \\
\hline S7 & M & 2 & 1 & 3 & 6 \\
\hline S8 & F & 0 & 0 & 6 & 6 \\
\hline S10 & F & 0 & 4 & 2 & 6 \\
\hline S1 & F & 0 & 2 & 2 & 4 \\
\hline S5 & M & 0 & 0 & 4 & 4 \\
\hline S14 & M & 1 & 1 & 0 & 106 \\
\hline & F & 1 & 0 & 0 & \\
\hline & & 33 & 32 & 41 & \\
\hline & & & & & \\
\hline
\end{tabular}

\section{Topics Discussed}

In the span of a week, the first guest host introduced three topics or threads to which students responded, added additional information and conducted discussions. Students originated three of the discussion threads to which this guest or other students responded. The second guest host introduced four threads while students originated five. In the third session the guest introduced seven topics and the students introduced five. This information about the originators of the threads indicates that this was a discursive environment as opposed to a transmission model of information dissemination. Students and hosts participated together as opposed to the hosts serving as the dominant source of information. 
Table 3: Average number of responses to guest-initiated versus student-initiated discussion topics in the three sessions

\begin{tabular}{|c|c|c|}
\hline & $\begin{array}{c}\text { Responses to Guest } \\
\text { Initiated Posts }\end{array}$ & $\begin{array}{c}\text { Responses to Student } \\
\text { Initiated Posts }\end{array}$ \\
\hline GH1 & 10 & 7.25 \\
\hline GH2 & 8 & 3.4 \\
\hline GH 3 & 8 & 4.0 \\
\hline Average & $\mathbf{8 . 7}$ & $\mathbf{4 . 9}$ \\
\hline
\end{tabular}

However, as Table 3 indicates, the average number of responses to the posts initiated by students were about half as many as those responses to guest initiated posts. Students were more responsive to the guests than to each other. This is not a surprising result since students may have expected the guest to lead the discussion and take primary responsibility for responding to the posts made by other students.

The topics discussed through these sessions were highly pertinent to the notions of integrating technology into the curriculum, the course topic. Some examples of the discussion leads (subject headings) posted by students and guests are presented below:

- Middle School Differences

- Benefits of publishing educational materials on the web

- Hidden curriculum, K-12 and integrated technology

- What do YOU need?

- The miracles of email

- Using the Internet constructively in the classroom

- How different lessons use the Internet?

These threads represent the variety of topics discussed by students and guests. It can be argued that the course-instructor can him/herself initiate these topics within the course. However, it has been my experience that connecting students with virtual hosts provides motivation, renewed energy and a sense of valued discussion that an instructor can use to enhance the learning experience in a course. Students were exposed to and participated in elaborate discussions about a number of topics related to the course. These non-graded discussions were held outside the instructional time available in this face-to-face course. Other benefits of this process are that students could raise issues pertinent to their needs and choose among the guests and interact with those that best suited their interests. As discussed, while presenting the quantitative evidence, not all students interacted with all of the guests all the time. However, from an instructor's perspective, all students were provided with equal opportunity to interact with each guest. This instructional experience concurs with Ryder and Wilson's [30] position that the Internet should be viewed as an infrastructure, which brings together media, tools, people and information to expand the range of human capabilities. The larger goal was to encourage students to engage in social discourse, vocalize their concerns and articulate their needs using this medium that enables students to practice 
collegiality and professionalism. Several students also came away re-thinking the notion of instructional resources available in a classroom. They now include virtual resources available beyond the physical confines of their schools. Additionally, these posts/products require significant thought, processing, and reflection. The act of posting itself creates a sharable and communal artifact that enriches both the individual student and other participants in this discursive community. Further research is needed to assess student perceptions of the benefits of virtual guest hosts and the factors that lead to decisions regarding participation.

\section{E. Preparing Participants for the Online Experience 1. Preparing Guests to Moderate Student Groups}

All three hosts were informed that this was a new instructional variation of using web-based conferencing in a graduate course. Each guest was e-mailed an inquiry about their interest in hosting the discussion group for a week. Upon expressing consent, each host was contacted for an in-depth discussion by email, telephone or in-person. Clearly, there are no established guidelines for virtual guest-hosts. Consequently, the general agreement was that we would try to adapt as needed to unanticipated outcomes. Time commitments of hosting were discussed and each host was asked to independently decide how often they would post and whether they would respond to each post. From the time stamp on the posts, it appears that almost all guests checked in daily and responded to the questions posted by students. Cotlar and Shimabukaro [31] concluded following their use of online experts that personalization and readability strongly influenced the responsiveness on the part of students. In this course, the guest responses were targeted toward answering specific questions asked, thus providing the students with a very personalized answer.

The hosts were also provided with a technical introduction to the web-based software, Hypergroups. They were provided general information about the students in the course and guidance about moderating. Matching student needs to the abilities of the hosts is an obvious but important factor when considering such environments. All three guests were able to provide web-based evidence to support their arguments, suggestions or examples. For example, while discussing the miracles of email, the conversation turned to free web-based conferencing systems available for use in local schools. The host provided students with pointers to such free services and elaborated upon possible uses.

The main concern, expressed in informal feedback from the guests, was that not all students participated, a concern that could easily be said of a face-to-face presentation. However, all of them reported that they enjoyed the experience and that it was not a load on their time commitments. Their closing comments to the students in the class indicated that they were disappointed in having to leave. Excerpts from the final postings by the three guests are provided to support the previous statement.

Tomorrow will be the last day that we are to have our discussions. I have enjoyed the talk very much. I plan to lurk on your future discussions because I want to see how your work progresses. GH1

Thanks to all of you for the discussion. I hope that we have at least thrown some things on the table that will keep us all thinking. - GH2 
I want to say right now that this has been one of the most fun things I've done in a long time! I'm glad I said yes to this project. I would enjoy hearing from you past this class. - GH3

\section{Preparing Students to Participate in Discussions with Guests}

Students were informed about participation in these forums as well. The instructor explained that these forums were created for them to vocalize their concerns about integrating technology, discuss issues, raise questions about successful models of technology adoption and inquire about systems to support schoolwide adoption of technology. Participation was encouraged but not mandated (graded). Prior to each session, students were provided with information (home pages) about each of the guest hosts and were asked to study this information as background for appropriate questions to ask within the general scope of the course.

\section{CONCLUSION}

This experience was valuable for students, guest hosts and the instructor in this graduate course. Students were engaged in discussions about topics that were highly pertinent to the course. They were introduced to new topics and were provided with opportunities to discuss real-life examples of integration. The instructor benefited by the presence of three hosts who addressed topics central to the course in meaningful ways.

In future iterations, it will be interesting to conduct a formal evaluation of student's reactions to the virtual guest experience. Factors to consider are the qualities they seek in an online guest, expectations about the immediacy of the response, factors that influence participation and the value attached to these conferences. Additionally, it will be interesting to study the sharing of knowledge that occurs in these learning environments through a study of the content of the messages.

\section{REFERENCES}

1. Bourne, J. R. Net-Learning: Strategies for On-Campus and Off-Campus Network Enables Learning. Journal of Asynchronous Learning Networks, 2 (2), 70-88, 1998.

2. Couples, C. Academic Infotecture: Course Design for Cyberschool. Paper presented at the Annual Meeting of the Southern Political Science Association, Atlanta, Georgia. (ERIC Document Reproduction Service No. ED 403 854), 1996.

3. Owston, R. The World Wide Web: A Technology to Enhance Teaching and Learning? Educational Researcher, 26 (2), 27-33, 1997.

4. Trentin, G. Internet: Does it Really Bring Added Value to Education? International Journal of Educational Telecommunications, 2 (2/3), 97-106, 1996.

5. Bothel, R., and Enfinger, J. You Don't Have to go the Whole Distance. T.H.E. Journal, 27(2), 115-8, 1999.

6. Pea, R. Seeing What We Build Together: Distributed Multimedia Learning Environments for Transformative Communications. Journal of Learning Sciences, 3 (3), 285-299, 1994.

7. Hiltz, S. R. Correlates of Learning in a Virtual Classroom. International Journal of Man-Machine Studies, 39, 71-98, 1993.

8. Chen, L. Distance Delivery Systems in Terms of Pedagogical Considerations: A Reevaluation. Educational Technology, 34-38, July-August, 1997.

9. Cook, D. L. Community and Computer-Generated Learning Environments. New 70.

10. Directions for Adult and Continuing Education, 67, 33-39, Fall, 1995.

11. Deal, N. Is the Medium the Message? Comparing Student Perceptions of Teacher Responses via Written and E-mail Forms. (ERIC Document Reproduction Service No. ED 392 432), 1995.

12. Johnstone, S. M., and Krauth, B. Balancing Quality and Access: Some Principles of Good Practice for the Virtual University. Change, 28 (2), 38-41, March, 1996. 
13. Kerka, S. Distance Learning, the Internet, and the World Wide Web. Washington, DC: Office of Educational Research and Improvement. (ERIC Document Reproduction Service No. ED 395 214), 1996.

14. Picciano, A. G. Developing an Asynchronous Course Model at a Large, Urban University. Journal of Asynchronous Learning Networks, 2 (1), 1-14, 1998.

15. Schrum, L. Online courses: What have we Learned? Paper presented at the World Conference of Computers in Education, England. (ERIC Document Reproduction Service No. ED 385 245), 1995.

16. Simich-Dudgeon, C. Developing a College Web-Based Course: Lessons Learned. Distance Education, 19 (2), 337-357, 1998.

17. Sullivan, E. Campus Technology Trends. Educational Record, 78 (1), 35-36, 1997.

18. Green, K. C. and Gilbert, S. W. (1995). Great Expectations: Content, Communications, Productivity, and the Role of Information Technology in Higher Education. Change, 27 (2), 8-18.

19. Boettcher, J. and Cartwright, C. G. Designing and supporting courses on the web. Change, 29 (5), 62-66, September, 1997.

20. Noam, E. M. Electronics and the dim future of the university. Science, 270 (13), 247-249, 1995.

21. Bourne, J. R., McMaster, E., Rieger, J. and Campbell, J. O. Paradigms for On-Line Learning: A Case Study in the Design and Implementation of an Asynchronous Learning Networks (ALN) Course, 1 (2), 38-56, 1997.

22. Dede, C. Distance learning $\rightarrow$ Distributed learning: Making the Transformation. Learning and Leading with Technology, 25-30, April, 1996.

23. Rowntree, D. Teaching and Learning Online: A Correspondence Education for the 21st Century? British Journal of Educational Technology, 26 (3), 205-15, 1995.

24. Simonson, M. Distance education: Does Anyone Really Want to Learn at a Distance? Contemporary Education, 68 (2), 104-7, 1997.

25. Boettcher, J. V. Internet pitfalls: What Not to Do When Communicating With Students on the Internet. Syllabus, 46-52, November/December, 1997.

26. Collins, M. and Berge, Z. Facilitating Interaction in Computer Mediated Online Courses. Paper presented at the FSU/AECT Distance Education Conference, Tallahassee, Florida, June, 1996.

27. Miller, R and Robin, B. HyperGroups: A New Tool for Enhancing Communication in an Electronic Community of Learners, 1999. http://coe.uh.edu/projects/cow/hypergroups.html

28. Selfe, C. Technology in the English Classroom: Computers Through the Lens of Feminist Theory. As reported in Ruberg, L. F., Taylor, C. D. and Moore, D. M. (1996). Student participation and interaction on-line: A case study of two college classes - Freshman writing and a plant science lab. International Journal of Educational telecommunications, 2 (1), 69-92, 1990.

29. Oliver, R. and Reeves, T. C. Dimensions of Effective Interactive Learning with Telematics for Distance Education. Educational Technology Research and Development, 44 (4), 45-56, 1996.

30. Ryder, M., and Wilson, B. Affordances and Constraints of the Internet for Learning and Instruction. Presentation to the joint session of the Association for Educational Computing. Feb., 14-18, 1996. http://www.cudenver.edu/ mryder/aect_96.htm

31. Cotlar, M., and Shimabukaro, J.N. Stimulating Learning with Electronic Guest Lecturing. Interpersonal Computing and Technology, 1(1). http://jan.ucc.nau.edu/ ipct-j/1993/n1/cotlar.txt

\section{ABOUT THE AUTHOR}

Siva Kumari is Assistant Dean and Director of Programs at the School of Continuing Studies, Rice University, Houston, Texas. The content for this paper comes from her position as a Research Assistant Professor at the University of Houston where she taught graduate-level online courses in Instructional Technology at the College of Education. Her doctoral dissertation was entitled "A study of higher education faculty using web-based teaching" was completed in 1998. 